\title{
Popular Literature Trends and the Digital Game of the 1990s
}

\author{
Xiping Zhang ${ }^{1, *}$ \\ ${ }^{I}$ Faculty of Chinese Language and Literature, Northwest Minzu University, Lanzhou, Gansu 730030, China \\ *Corresponding author.Email:547043941@qq.com
}

\begin{abstract}
There is an internal relationship between the popular literature trend in the 1980s-1990s and the production and success of the first batch of domestic digital games in the 1990s. First of all, the pursuit of freedom and the demand for spiritual release reflected in this literary and artistic trend echo the characteristics of role-playing games. Secondly, the popularity of swordsmen novels and romance novels influenced the theme and content design of digital games in this period. Thirdly, the acceptance of popular literature has laid the aesthetic foundation for the popularity of certain digital games, and the acceptance of Hong Kong and Taiwan culture in the mainland has also played an important role.
\end{abstract}

Keywords: 1990s, Popular literature, Hong Kong and Taiwan literature, Digital games.

\section{INTRODUCTION}

From the late 1970 s to the early 1980s, the domestic ideology and culture underwent great changes along with the political and economic transition. People began to rethink the relationship between literature and people. At that time, various literary trends re-emerged, including the revival of popular literature.

However, the upsurge of popular literature in this period is particularly special, as Lu Guishan said, "mainly the popular literature introduced from Hong Kong, Taiwan and overseas and the revival of traditional popular literature, as the undercurrent of folk culture surging outside the main culture"1. ${ }^{\text {. }}[1]$ Among them, the most important was the introduction of popular literature from Hong Kong and Taiwan. At that time, Hong Kong and Taiwan literature (Jin Yong's martial arts, Qiong Yao's romance, San Mao's prose, etc.) carried language style, emotion expression and theme transmission completely different from that of inland literature, which immediately impacted the inland book market and even caused widespread piracy. In the 1990s, the introduction and distribution of popular

1. Lu Guishan, The Contemporary Thought of Literature and Art in China, Beijing: Renmin University of China Press, May 2014, p343. literature gradually leveled off from the state of rapid expansion, formed a relatively mature market operation, also formed a stable and considerable number of audience groups, and started a period of prosperity.

In the 90s, is also the time of research and development of Chinese digital games rise, both mainland and Taiwan, all output now regarded as classics and classic IP Digital game, such as Chinese Paladin: Sword and Fairy, Xuan-Yuan Sword, Rich Man, Heroes of Jin Yong, Legend of the Swordman, Guan Du. The design and success of some of these games, it seems, has something to do with the popularity of popular literature at the same time, which influenced not only the themes and content of game creation, but also the types of games that digital games chose to make.

\section{SPIRITUAL RELEASE AND THE RISE OF RPGS}

The six digital games mentioned above are all classics of the 1990s, among which the most famous are Chinese Paladin: Sword and Fairy, Xuan-Yuan Sword, Legend of the Swordman and Heroes of Jin Yong. The first three are even collectively referred to as the "Three Swords Made in China", in recognition of the achievements 
achieved in the early development of digital games in China. All four games, however, are RPG types.

RPG (role-playing game) is a type of game divided by game mode, which is called "roleplaying game" in Chinese. As the name suggests, the player takes on a role as a story player, participating in the narrative progression of the game, and fulfilling the conditions required to achieve a given or open-ended ending. RPG-style games in digital games typically have plenty of story and text to allow the player to relate to a sense of emotion and identity. That said, there are two core elements in an RPG: role-playing and a complete setting and story. This is one of the most prominent design features of these games, and the key to their popularity.

Role-playing behavior in digital games without affecting the normal life order, brought players into another identity, another kind of life experience, so no matter what was framed in game design degrees of freedom of action in the range, for players, role play itself has been a preliminary release of free spirit.

This quest for spiritual release is exactly what readers sought in popular literature in the last century. The 1980s and 1990s were a period of reflection and backlash to the Cultural Revolution. After the cultural and political turn, the masses' pursuit of individuality, personal emotion and political expression, which had been suppressed for a long time, were in urgent need of reasonable expression and realization, which was also the root of the emergence of various literary thoughts in this period. Compared with the reading and writing of pure literature under modernism, humanism and liberalism, the general public is obviously more receptive to the influence that popular literature can bring. The free spirit of swordsman novels and the perceptual expression of romance novels, as well as the distinct feelings and dislikes shared by them, have made readers obtain unprecedented spiritual satisfaction.

Fictional literature gives readers an imaginary space to invent their personal identity. Readers can put their own emotions and value judgments into the reading process and wander in another time and space. This feature of literature and art has been understood since Liu Xie wrote "the form is above the river and sea, the heart is under the Wei fault". However, the identity role substitution and life imagination that can be realized in the text reading are only slightly scratching the surface after all. Only the role playing that can be actually controlled can make people more easily forget all kinds of limitations and difficulties in reality. Role-playing games echo and compensate for the role and regret of novel reading in this respect.

RPG games allow players to play an important role in the story, participate in the process of the whole story, and even influence the development trend of the story, so as to realize the temporary transformation between the real identity and the virtual identity, and experience the real experience of another identity in the fictional space. Readers reading "biography of the Condor Heroes", or in the heart will be eager to become Guo Jing such chivalry and national hero, and as a sage and lover Huang Rong to achieve the ideal together; And in the digital game Chinese Paladin: Sword and Fairy, player can act a man named Li Xiaoyao, who is a martial arts genius, carry 3 bosom friends of beauty to roam in each place, make a swing, become a generation warrior and the person that save the world as the advance of experience practice and plot.

It can be said that when an individual chooses a type of game, it is a way to adjust his spirit and will, which can reflect his internal needs in a period of time. The choice of leisure puzzle games is to kill the boring space and time, the choice of fighting and shooting games is often the vent of the remaining energy, the choice of role-playing games, it hides the individual's weariness of the existing life and the yearning for fresh experience that has nothing to do with the real interests. For game makers and players in the '90s, one possible psychological state of mind for choosing an RPG was the desire to break through a life that had begun to turn but had not yet been fully unshackled (both culturally and spiritually).

Of course, role-playing has to be supported by a complete background and plot. Popular literature from the 1980s and 1990s also helped develop RPGs, such as Jin Yong's 14 books, The Legend of the Legend of Jin Yong. This, in turn, leads to the question of how popular literature has influenced the theme and content design of digital games in the '90s.

\section{CHIVALROUS AND EMOTIONAL: THE COMMON EXPRESSION OF THE TWO ARTS}

Of the digital games released in the 1990s, one of the most obvious examples of the influence of popular literature is Heroes of Jin Yong, released in 
1996. This game takes the main plots or images in the 14 novels of Jin Yong as the main plot, and adds a small amount of original content to fit the discordant points among the 14 novels and provide a reasonable explanation for the plot design.

At the beginning of the game, a character named by the player himself/herself wakes up in an ancient room and is told by the "soft doll" that he has "traveled" into the Virtual Reality space of the digital game he bought previously. Only by finishing the game can he return to Reality. The prerequisite for completing the game is to collect all 14 books. The non-player character of the game provides the key clue: "飞雪连天射白鹿, 笑书神侠倚碧 驾", which is a couplet formed by the initials of all 14 novels of Jin Yong. In the game, players can use their favorite name to travel to classic locations in the original book, such as Mount Hua, Shaolin Temple, and Swordman's Island, and meet, get to know, and become teammates with characters in the book as they travel through the game world. At the same time, players will give their own image, the ability to participate in the classic events based on the original work, such as competition on Huashan, Yang Guo to find Xiao Longnv and so on.

Heroes of Jin Yong is one of the products of the "Jin Yong fever" in the 1990s. It can be seen how the craze caused by Jin Yong's novels led the reading interest and concern of a generation. It can also be seen from this case how the current trend of popular literature at that time affected the expression of the newly emerging digital art. However, the popular literature trend active in the 1990s, especially the martial arts novel craze, has a deeper and richer influence on the theme design and content plot arrangement of digital games than this case shows.

When discussing martial arts novels, Tan Guanghui once mentioned that "the core spirit of wuxia is freedom, among which nationalism and heroism are most prominently integrated. Nationalism and heroism can be seen as an extension and development of the nationalism and heroism sentiments of the 1960s and 1970s "2.[2] This is true, but the origin of nationalism and heroism in wuxia is actually more profound, which is not only from the special context of 1960s and 1970s, but also from the idealistic and spiritual tradition set by Si Maqian when he arranged the biography of the knightly ranger. The martial arts

2. Tan Guanghui, Martial Arts Novels and the Free Spirit of Mass Culture in the 1980s, Journal of Hainan Normal University, No.2, 2016, p41. novels of Jin Yong and $\mathrm{Gu}$ Long add a new expression and pay more attention to the substitution of traditional cultural elements, which makes the martial arts novels, which were originally pleasant in the market, add a lot of cultural connotation and win the audience's favor more.

The nationalism, heroism and traditional elements in the martial arts novels popular in the 1980s and 1990s are exactly in line with the development needs of domestic digital games in this period. At that time, the Chinese game industry was booming, but "it was the Japanese time when Nintendo, Sega, PC-E and other game companies established the global gaming hardware hegemony system based on the Japanese standard" 3 ,[3] and Chinese people could only play digital games from abroad. People gradually realize that cultural colonization is also a problem in the field of games. The pirated game market in China "actively copies the colonial market pattern without 'domestic products' since the Opium War" ${ }^{4}$.[3] Therefore, in the context of the agitation of nationalist discourse and emotions, China urgently needs to create its own cultural-themed digital games. Dr Deng Jian listed in the paper from 1994 to 1998 of China made the first batch of domestic game statistics (statistics does not include Taiwan), which contains more than half of all the "image" in China.

The most famous of these is Legend of the Swordman, which follows in theme and setting the same lines as Jin Yong's novels, especially Tian Long Ba Bu, Legend of the Condor Heroes and The Romance of the Condor Heroes, which show the Song Dynasty's resistance against foreigners. The background of the game is set in the period of Yue Fei's resistance against the Jin Dynasty in the Southern Song Dynasty. The story revolved around the hatred of Dugu Jian, a disciple of the Hengshan Sword School. The final result is "Qin Hui was killed in the storm pavilion, and Yue Fei attacked Huang Long's palace". As the first mature martial arts role-playing game developed in the mainland, Legend of the Swordman integrates the core of martial arts with the spirit of nationalism and heroism, and adds abundant Chinese elements from character lines to shape design. It can be said that Legend of the Swordman is not only the influence product of Jin Yong's martial arts prosperity, but also the demand product of domestic game

3. Deng Jian, The Origin and Research of Chinese Video Game Culture, Shanghai Culture, No.12, 2020, p44.

4. Id. 
development to regain the right to speak. Besides, the characters and plot are full, so it is also widely loved.

The Taiwan game Chinese Paladin: Sword and Fairy (the first generation), which was not included in Deng Jian's statistics, is also the representative work of the martial arts theme of this period. In the Chinese Paladin 1, the player needs to play a pair of mandarin duck knighty couple's descendants $\mathrm{Li}$ Xiaoyao, in the fate of the drive to loitering rivers and lake, hoe the strong and the weak, in the dispute between right and wrong good and evil under the defense of their feelings. In this all the way, as Li Xiaoyao, player not only need to face the identity of people and demon different way and emotional return, but also need to help Nanzhao country to eradicate the evil party, help the world people, achieve the double cultivation of personal martial arts and values, and eventually become a new generation of sentient beings and righteous warrior. It can be seen that the martial arts world of Chinese Paladin I is also built on the national and national principles and on heroism.

Another element that was evident in Chinese Paladin 1 that also stood out in the '90s is romance. The word "言情" in modern and contemporary literature, also known as romance in English, can be commonly understood as romantic love stories. In the game, as the Li Xiaoyao of big male master, around appeared three characters, the female of each different identity, respectively for Zhao Linger, Lin Yueru, a nu. The Zhao Linger that acts as $\mathrm{Nu}$ Wa later generations is $\mathrm{Li}$ Xiaoyao's marriage husband and wife originally, lose memory because of Li Xiaoyao however, hold a hate to be shut into "lock bewitching tower", because suppress water monster perishes again finally. As the daughter Lin Yueru of Wu Lin alliance Lord it is Li Xiaoyao the confidante during memory loss, accompany $\mathrm{Li}$ Xiaoyao travel around, leave "eat old, play old" classic lines, die in the process of rescue Zhao Linger finally. As a white Miao girl who believed in NuWa, Anu was the youngest girl in the story. She was also one of the important companions of $\mathrm{Li}$ Xiaoyao in the later period. Li Xiaoyao's love affair is full of romance and legend color, there is no lack of twists and turns of the stories of talented people and beautiful women, really for this generation of games in the "romance" model.

In the trend of popular literature in the 1990s, romance novels occupy a full weight. Although no digital games of the 1990s were actually adapted from romance novels, it is certain that there were a lot of "romance" elements in digital games of this period, which were usually combined with martial arts games, in the form of "martial arts + romance" content and plot arrangement. This is more or less influenced by the current popular plot pattern and style of love.

The plot pattern of "martial arts + romance" was also found in martial arts novels, and Gu Long's works are the best representative. In $\mathrm{Gu}$ Long's novels, the twists and turns of various characters' affairs often occupy the author's large amount of ink, which makes the description of various types of love in $\mathrm{Gu}$ Long's wuxia novels often remembered by people instead. In Gu Long's novels, men and women are in the mood, no taboo, and the rare love is even more engraved on my heart. White jade tiger in, Zhao Wuji to Wei Fengniang's emotion then led to the author that classic: "lovesickness has made people lingering to the bone, decast, dare not lovesickness is what taste " $^{5}[4]$ The saying goes "Even heroes fall for beauties", also then should and "martial arts + romance" rationality.

The love of Qiong yao style is similar to the love of digital games in spirit, which reflects people's demand and release of erotic desire, and the pursuit of real emotional feelings. The love between men and women in Chinese Paladin 1 is the love between a man and many women, but it is by no means excessive love, on the contrary, it reflects the purity and sincerity of the character. As Li Jiandong said, "At that time, Taiwan and Hong Kong had completely different ideologies and value judgment standards from the mainland, and the discourse of political power was relatively weak. Therefore, no matter about martial arts, love, or exotic customs, they could write freely and honestly." ${ }^{6}[5]$ Both in popular novels and digital games, the expression of swordsman and love reflects the subversion of the traditional form of discourse.

\section{THE ACCEPTANCE FOUNDATION LAID BY POPULAR LITERATURE}

The trend of popular literature at the end of last century not only has an inseparable relationship

5. Gu Long: White Jade Tiger, Henan Literature and Art Publishing House, May 2013.

6. Li Jiandong: Reflection on the Popular Mainland in the 1980s and 1990s of Jin Yong, Qiong Yao and Sanmao's Works, Journal of College of Literature, Nanjing Normal University, 2011, 1, p. 95. 
with the types and content design of digital games, but also affects the acceptance of digital games among the public. Popular literature works from Hong Kong and Taiwan were introduced into the mainland in the early 1980s, and soon set off a new upsurge of reading in the mainland. The works of Jin Yong, Qiong Yao and San mao became popular classics for a short time, with a very wide audience and a strong momentum and a long influence, which did not stop until the 1990s. The popularity of popular literature in the past decade has also cultivated the new aesthetic and acceptance tendency of mainlanders.

Once upon a time, and low literature has the upper hand in battle is necessarily elegant literature, popular fiction, because of its language and subject always considered of the difficult to appeal to the literature, popular literature ideological trend rise in the 80s, however, are giving the literature and a new chance to challenge the elegant literature existence space, people in the period of review and self-verification, It also reconsiders and explores the expression boundary of literature and art. "Popular literature has not only seized the reading group and market of elegant literature, but also changed the inertia of contemporary readers' literary aesthetics without feeling" ${ }^{7}$.[6] Thus, the new swordsmen and new love have been put on the table and entered the vision of all people.

This is a thematic style of digital games that can be popular and become classic aesthetic forerunner. According to Dr Deng Jian statistics, between 1994 and 1998, China issued in total 39 games, which includes the anti-japanese patriotic theme works, including the west division A subject matter works of "great China" and so on movement, However, it is the four role-playing games that have finally become the classics of The Times, namely Legend of the Chinese Paladin, XuanYuan Sword, Heroes of Jin Yong, Legend of the Swordman. As soon as the first two games were published, they were reported by DaZhong Software, which attracted the attention of the industry.

These four digital games are different from other mainland games in seeking a grand narrative, but have the general aesthetic characteristics of popular novels: complete plots, romantic stories, and entertaining functions. In the form of roleplaying entertainment between such games, just like reading a novel, you can enjoy different

7. Lu Guishan, The Contemporary Thought of Literature and Art in China, Beijing: Renmin University of China Press, May 2014, p356. experiences in the fantasy world, experience the strange world and extraordinary life, to achieve a kind of psychological satisfaction. And this kind of psychological satisfaction is also in line with people's demand for spiritual release in that era. It can be said that the success of these four works, to some extent, is due to the success of the new chivalry and new romance in the same period.

In terms of the success of Chinese Paladin, XuanYuan Sword, and Heroes of Jin Yong, people's acceptance of Hong Kong and Taiwan culture still has an impact. China cultural revolution havoc ten years to make the development of economy and culture was once a standstill, also makes the search for national and traditional culture identity psychology by certain obstacles, and both belong to the Chinese culture of Hong Kong, Taiwan and another kind of charm, showing at this time to become the search for cultural identity of an alternative channel. One of the reasons for people's recognition of Jin Yong's wuxia lies in the fact that Jin Yong's wuxia has traditional cultural elements and strong sense of history.

This cultural recognition and pursuit also extends to digital games, as evidenced by the success of the Xuan Yuan Sword series produced by Taiwan Daewoo. As one of the top ten ancient artifact in the game, whether the Xuan Yuan Sword endowed with the name of the game really exists in history and myth is actually impossible to test. But the image of Xuan Yuan Sword itself sets the history and myth-based style of the series. The first version of Xuan Yuan Sword was released in 1990 and was considered unfinished due to its incomplete plot. It was not until the release of the second generation of Xuan Yuan Sword in 1994 that the foundation of the series was laid. From the scene production, image design to the script, Xuan Yuan Sword 2 has a complete "Chinese style" elements. As the monsters of the battle opponents, the snake and dumpling turtle are also selected, which are derived from the Classic of Mountains and Seas, making the game itself feel like roaming in the strange stories of different dynasties and generations. In 1995, the release of Xuan Yuan Sword: Maple Dance set the background of the story for the sixth year of King Weilie of the Warring States Period, when Mozi's disciple Fu Ziche set out on a journey because of the discovery of the plot of Guiguzi disciples. This work also because of its historical structure and the presentation of the mechanism of the art, the Xuan Yuan Sword series of public reputation to the peak. Due to its ink painting style, a large number of 
traditional mythological elements and a clear historical structure, Xuan Yuan Sword has become the favorite of those who seek Chinese tradition. Therefore, Xuan Yuan Sword has won a lot of audiences in the mainland.

\section{CONCLUSION}

The content design and popularity of a single digital game are indeed accidental factors, but the same type of works in the same period can be successful, there must be a common driving force, this driving force is not only the market economy, but also lies in the needs of cultural psychology. For the early generation of domestic digital games in the 1990s, it was the trend of popular literature and the cultural psychological factors behind it that played a key role, and became an important influencing factor in the design and popularity of digital games in this period, which echoed with each other. Facing up to the relationship between different arts will also provide us with solvable equations for further understanding of the various mechanisms of a type of art.

\section{AUTHORS' CONTRIBUTIONS}

This paper is independently completed by Xiping Zhang.

\section{REFERENCES}

[1] Lu Guishan, The Contemporary Thought of Literature and Art in China, Beijing: Renmin University of China Press, May 2014, p343.

[2] Tan Guanghui, Martial Arts Novels and the Free Spirit of Mass Culture in the 1980s, Journal of Hainan Normal University, No.2, 2016, p41.

[3] Deng Jian, The Origin and Research of Chinese Video Game Culture, Shanghai Culture, No.12, 2020, p44.

[4] Gu Long: White Jade Tiger, Henan Literature and Art Publishing House, May 2013.

[5] Li Jiandong: Reflection on the Popular Mainland in the 1980s and 1990s of Jin Yong, Qiong Yao and Sanmao's Works, Journal of College of Literature, Nanjing Normal University, 2011, 1, p. 95.

[6] Lu Guishan, The Contemporary Thought of Literature and Art in China, Beijing: Renmin University of China Press, May 2014, p356. 